\title{
Printed by Parkinson's: a neurological art project linking patient stories and biosignals
}

\author{
Lucia K. Feldmann ${ }^{1}$ (1) and Andrea A. Kühn 1,2,3,4*
}

\begin{abstract}
"Printed by Parkinson's" is an innovative project with the main aim to raise awareness for the many aspects of Parkinson's disease and their implication for everyday life. In a cooperation of Innocean Worldwide $\mathrm{GmbH}$ and the Movement Disorder and Neuromodulation Section, Charité Universitätsmedizin Berlin, design and medical and neuroscientific expertise were combined to create unique artworks: Bronze sculptures were created when combining personal objects selected by each patient, and their neurophysiological individual health data. As a core element, patient interviews in an accompanying film shed light on the personal stories behind the art objects. Public presentations raised interest in the topic and very positive reactions by patients and relatives, and we think that the possibility to use art for improved communication in the field of medicine holds promise for the future.
\end{abstract}

Keywords: Patient outreach, Parkinson's disease, Art

\section{Introduction}

Parkinson's disease (PD) is a condition which changes the patients' lives in many aspects. While PD is a routine diagnosis for neurologists, for patients, the diagnosis may initially raise fears and negative images of disability and decay. Coping with the various motor and nonmotor symptoms is a long process accompanied by many visits to the hospital and continuous therapy adjustments. Medical therapies themselves may be demanding, with side-effects such as impulse control disorders and severe fluctuations dictating the daily life. However, taking the decision for advanced invasive therapies such as deep brain stimulation is often a long process for each patient and his family. The impact of
PD on the emotional and social life - for the patients and their relatives - is often underestimated.

Patients and their histories are an incredibly valuable resource for helping PD patients and their families in the many stages of the progressing disease. One important way to use this resource are support groups, but here, we took a different approach: In cooperation with an international communications company [2], we developed an arts project for which sculptures were created by merging neuroscience and design. Very personal patient stories were captured in compelling interviews about the PD patients' lives with the disease, with the aim to raise awareness for the many layers of this common neurological disorder.

\footnotetext{
* Correspondence: andrea.kuehn@charite.de

'Department of Neurology, Charité Universitätsmedizin Berlin, corporate member of Freie Universität Berlin, Humboldt-Universität zu Berlin, and Berlin Institute of Health, Charitéplatz 1, 10117 Berlin, Germany

${ }^{2}$ Berlin School of Mind and Brain, Humboldt-Universität zu Berlin, Berlin, Germany

Full list of author information is available at the end of the article
}

\begin{abstract}
Making-off "Printed by Parkinson's"
"Printed by Parkinson's" was an intensive and exciting project bringing together creative minds in design, film, photography, neuroscience, medicine and, importantly, the patients. Six PD patients from our out-patient clinic were asked to name an object that had become difficult to use due to PD and had a personal meaning to them.
\end{abstract}

(c) The Author(s). 2020 Open Access This article is licensed under a Creative Commons Attribution 4.0 International License, which permits use, sharing, adaptation, distribution and reproduction in any medium or format, as long as you give appropriate credit to the original author(s) and the source, provide a link to the Creative Commons licence, and indicate if changes were made. The images or other third party material in this article are included in the article's Creative Commons licence, unless indicated otherwise in a credit line to the material. If material is not included in the article's Creative Commons licence and your intended use is not permitted by statutory regulation or exceeds the permitted use, you will need to obtain permission directly from the copyright holder. To view a copy of this licence, visit http://creativecommons.org/licenses/by/4.0/. 

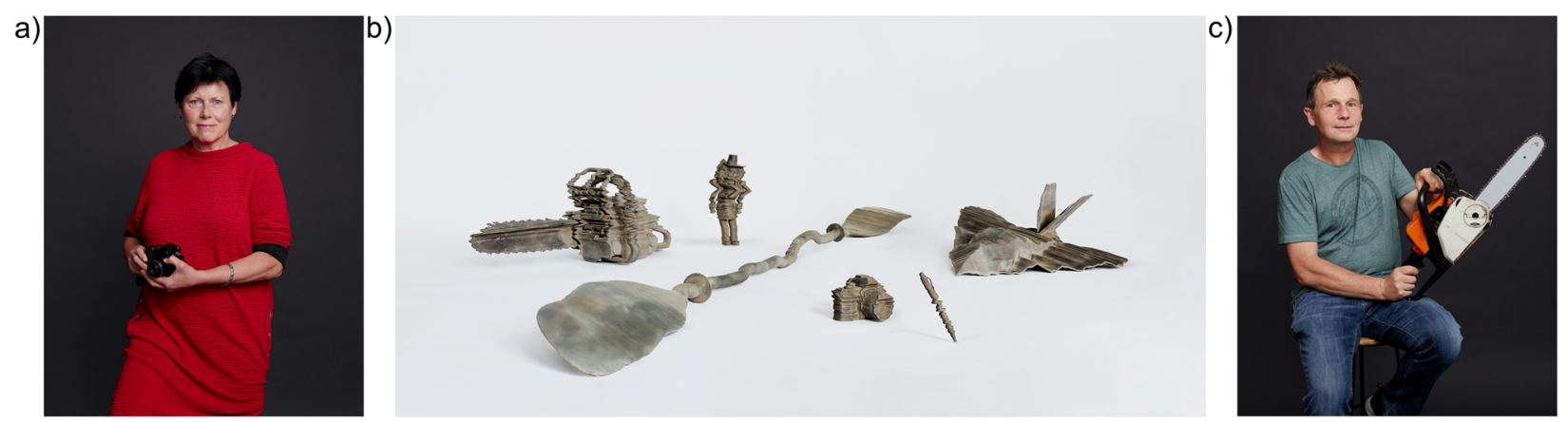

Fig. 1 Printed by Parkinson's - design and patients' personal stories. Patients selected different objects representing their experience with PD: a a camera symbolizes difficulties and reacquisition of creative expression for this patient; c for the passionate former motorcyclist, using the chainsaw for handicraft and gardening is a favorite occupation beside rock-climbing, which he even started after the diagnosis. Individual electrophysiological data and selected objects were used to create unique bronze sculptures (b). Photographs were taken by Ender Suenni (photographer, Cosmopola $\mathrm{GmbH}$ )

The result was an interesting variety $($ Fig. $1 \mathrm{a}+\mathrm{c})$ : while one patient selected a camera which had helped her continue with her creativity, another patient selected a nutcracker which he had loved to build but was now struggling to construct with limited fine-motor skills. One patient chose a paddle, which he connected to PD because during medication induced impulse control problems he had ended up in distress, unable to navigate on the open sea.

For the project, we selected patients who had participated in electrophysiological recordings. All patients had received DBS and had participated in local field potential (LFP) recordings for clinical studies and research projects during the period of externalization in the twostaged DBS surgery. During this period, we used the opportunity to record LFPs from the deep brain target structures for DBS, in the case of PD, the subthalamic nucleus (STN). Research using these unique recordings has previously contributed to a better understanding of the pathophysiology underlying movement disorders $[3$, $4,6,7]$. Another data source were movement recordings using an accelerometer. Here, we re-used these patient data in order to create individual art objects reflecting the personal pathological activity and symptomatology. Specifically, a 3-D-printer was "inflicted" with the disease using the patient's individual electrophysiological data thereby creating individualized art objects [5]. The result are mesmerizing bronze sculptures from the objects that the patients had chosen (Fig. 1b).

The core element of "Printed by Parkinson's" is the film, which mainly consists of very personal interviews with the patients, as well as an interview with the head of the Movement Disorder Unit, Prof. Dr. Andrea Kühn. This film gives the patients the opportunity to tell their stories, their fears and struggles, their strategies for coping and how they won back their lives after the initial shock of the diagnosis. Together with clinical background information, this film has the potential to reach patients and their relatives on a more personal level and convey understanding, hope and support. The film can be viewed on the project website https://www. printedbyparkinsons.com and on the homepage of the Movement Disorder and Neuromodulation Unit, Department of Neurology, Charité Berlin.

\section{Reception and outlook}

The film and the sculptures were first displayed publicly on World Brain Day at a vernissage and exhibition in the Alte Münze, a renowned museum space in the center of Berlin. It was furthermore presented during support group and charity events. Art prints and sculptures are now on display at the department of Neurology, Charité, Berlin. While it was also a success in the field of design winning several prizes $[1,8]$, our true reward was the very positive feedback by patients and relatives. We hope that "Printed by Parkinson's" will continue to raise awareness for the personal side of PD at other exhibitions, e.g. the new Humboldt Lab in the Humboldt Forum in Berlin, and will motivate and support our PD patients. Through the combination of arts and neuroscience, we hope to multimodally achieve understanding and support for PD and other movement disorders.

\section{Abbreviations}

PD: Parkinson's disease; DBS: Deep brain stimulation; LFP: Local field potential; STN: Nucleus subthalamicus

\section{Acknowledgements}

We thank Marlon von Franquemont, Leonie Knorr, Sanja Colli and Ender Suenni for their creativity and positive energy in making this project happen.

\section{Authors' contributions}

L.K.F. participated in implementation and organization of the project, and was a major contributor in writing the manuscript. A.A.K. conceptualized the project and led its implementation, and reviewed the manuscript. All authors read and approved the final manuscript. 


\section{Funding}

No Funding.

\section{Availability of data and materials Not applicable.}

\section{Ethics approval and consent to participate}

All patients approved of participation in the arts project including video recordings, photography and data exchange to Innocean Worldwide $\mathrm{GmbH}$, Berlin, Germany, Cosmopola GmbH, Berlin, Germany, mediamonks GmbH, Amsterdam, The Netherlands.

For creation of the art objects, data from electrophysiological recordings which had been previously performed for clinical studies in the Movement Disorder and Neuromodulation Section of Charité Universitäsmedizin Berlin was used in accordance with renewed patient consent. All studies had an approval by the local ethics committee of the Charité Universitätsmedizin Berlin.

\section{Consent for publication}

The patients gave consent for publication.

\section{Competing interests}

L.K.F. reports no competing interests.

A.A.K. declares that she is on the advisory board of Boston Scientific and Medtronic and has received honoraria from Boston Scientific, Medtronic, Abbott, Teva und Ipsen.

\section{Author details}

'Department of Neurology, Charité Universitätsmedizin Berlin, corporate member of Freie Universität Berlin, Humboldt-Universität zu Berlin, and Berlin Institute of Health, Charitéplatz 1, 10117 Berlin, Germany. ${ }^{2}$ Berlin School of Mind and Brain, Humboldt-Universität zu Berlin, Berlin, Germany. ${ }^{3}$ Deutsches Zentrum für Neurodegenerative Erkrankungen, Berlin, Germany. ${ }^{4}$ NeuroCure Clinical Research Centre, Charité Universitätsmedizin Berlin, Berlin, Germany.

Received: 17 July 2020 Accepted: 13 August 2020

Published online: 04 November 2020

\section{References}

1. Art Directors Club. (2020). Gewinner ADC Wettbewerb 2020. Retrieved from https:/www.adc.de/content/uploads/dlm_uploads/2020/05/ADC_ Wettbewerb_2020_Gewinnerliste.pdf. Accessed 16 July 2020.

2. innoceanberlin.com. Innocean Worldwide $\mathrm{GmbH}$ Berlin. Retrieved from www.innoceanberlin.com. Accessed 16 July 2020.

3. Kuhn, A. A., Kupsch, A., Schneider, G. H., \& Brown, P. (2006). Reduction in subthalamic $8-35 \mathrm{~Hz}$ oscillatory activity correlates with clinical improvement in Parkinson's disease. The European Journal of Neuroscience, 23(7), $1956-$ 1960. https://doi.org/10.1111/j.1460-9568.2006.04717.x.

4. Kuhn, A. A., Tsui, A., Aziz, T., Ray, N., Brucke, C., Kupsch, A., ... Brown, P. (2009). Pathological synchronisation in the subthalamic nucleus of patients with Parkinson's disease relates to both bradykinesia and rigidity. Experimental Neurology, 215(2), 380-387. https://doi.org/10.1016/j.expneurol. 2008.11.008.

5. mediamonks.com. Mediamonks website. Retrieved from www.mediamonks. com. Accessed 16 July 2020.

6. Neumann, W. J., Degen, K., Schneider, G. H., Brucke, C., Huebl, J., Brown, P., \& Kuhn, A. A. (2016). Subthalamic synchronized oscillatory activity correlates with motor impairment in patients with Parkinson's disease. Movement Disorders, 31(11), 1748-1751. https://doi.org/10.1002/mds.26759.

7. Oswal, A., Brown, P., \& Litvak, V. (2013). Synchronized neural oscillations and the pathophysiology of Parkinson's disease. Current Opinion in Neurology, 26(6), 662-670. https://doi.org/10.1097/WC0.0000000000000034.

8. The One Club for Creativity. (2020). The One Show: Awards 2020. Retrieved from https://www.oneclub.org/theoneshow/showcase/?discipline=2. Accessed 16 July 2020

\section{Publisher's Note}

Springer Nature remains neutral with regard to jurisdictional claims in published maps and institutional affiliations. 